\title{
Seventy-five years of Chromosoma: Ivory Towers, citation metrics, and longevity of research
}

\author{
Erich A. Nigg
}

Published online: 18 February 2014

(C) Springer-Verlag Berlin Heidelberg 2014

We are celebrating the 75th birthday of Chromosoma and surely this occasion calls for a few "words of wisdom" from the chief editor. Here they are.

My generation grew up with the Dylan song-The times they are a-changin'. I am tempted to add: and so is science and so is publishing. Scientists of past decades have often been accused to live in an Ivory Tower. To be honest, I have never quite seen what was wrong with that - it always seemed to me that Ivory Towers offer not only a sheltered setting, ideal for concentrating on an important scientific problem, but also a great view. But, then, is this really true? Would Galileo Galilei have gotten into trouble had he shut himself up in an Ivory Tower - or Charles Darwin for that matter? Be it as it may, modern scientists have definitely been driven out of the Ivory Tower (imaginary or real). One can find many good reasons for why this was necessary: foremost, scientists need to explain themselves to a general public - modern research costs a lot of money, often provided by charities and taxpayers, and these folks have a right to understand what basic research is all about. Equally important, voters in democratic countries need at least a rudimentary understanding of modern science- - how should they otherwise form an opinion about the pro's and con's of, for example, GMOs, novel vaccines, or stem cell therapies? Most of us scientists understand this need for outreach and many contribute more than their share to public education. So far, so good. But I also see a downside to having left the Ivory Tower (assuming that our ancestors inhabited such a stronghold in the first place...). To survive and prosper in the past, scientists were dependent primarily on the respect and recognition of their peers. To survive (get funded...) today, scientists increasingly crave the recognition of the

E. A. Nigg $(\bowtie)$

Biozentrum, University of Basel, Klingelbergstr. 50/70, 4056 Basel, Switzerland

e-mail: erich.nigg@unibas.ch media. As a consequence, it sometimes appears that publication of research results in peer-reviewed scholarly journals is no longer sufficient to attain recognition and funding. Instead, scientific visibility is sought through press conferences and media appearances, followed by reverberations in social media outlets. The quiet Ivory Tower has been substituted by the bustling Market Square. I doubt that all this hustling for attention is propitious for the scientific endeavor or that constant competition for limited "prime time" assures esteem for the best science. Rather, I suspect that the relentless quest for maximum impact (and the concomitant pressure to reach the finishing line ahead of competitors) contributes much to the alarming and widely publicized drop in research reproducibility.

This is where Chromosomaś 75 th anniversary comes in. If you look at "impact factor," one of the despotisms of modern times, Chromosoma is unlikely to be amongst the medal winners anytime soon. But Chromosoma does great when you use a somewhat different citation metric-longevity. Many important papers published in Chromosoma have not only been cited hundreds to thousands of times, but they are still cited today - some 50 or more years after publication! As a testimony, please consider the citation classics listed below.

The chief editor's pick of Chromosoma citation classics:

Beermann W (1952) Chromomerenkonstanz und spezifische Modifikationen der Chromosomenstruktur in der Entwicklung und Organdifferenzierung von Chironomus tentans.

Chromosoma, 5:139-198.

Cooper KW (1959) Cytogenetic analysis of major heterochromatic elements (especially Xh and Y) in Drosophila melanogaster, and the theory of "heterochromatin".

Chromosoma, 10:535-588.

Gall JG, Cohen EH, Polan ML (1971) Repetitive DNA sequences in Drosophila

Chromosoma, 33:319-344. 
Goodpasture C, Bloom SE (1975) Visualization of nucleolar organizer regions in mammalian chromosomes using silver staining.

Chromosoma, 53:37-50.

Schweizer D (1976) Reverse fluorescent chromosome banding with chromomycin and DAPI.

Chromosoma, 58:307-324.

Goto K, Maeda S, Kano Y, Sugiyama T (1978) Factors involved in differential Giemsa-staining of sister chromatids.

Chromosoma, 66:351-359.

Harper ME, Saunders GF (1981) Localization of single copy DNA sequences on G-banded human chromosomes by in situ hybridization.

Chromosoma, 83:431-439.

Earnshaw WC, Rothfield N (1985) Identification of a family of human centromere proteins using autoimmune sera from patients with scleroderma.

Chromosoma, 91:313-321.

Tautz D, Pfeifle C (1989) A nonradioactive in situ hybridization method for the localization of specific RNAs in Drosophila embryos reveals translational control of the segmentation gene hunchback.

Chromosoma, 98:81-85.

Loidl J, Nairz K, Klein F (1991) Meiotic chromosome synapsis in a haploid yeast.

Chromosoma, 100:221-228.

Hendzel MJ, Wei Y, Mancini MA, Van Hooser A, Ranalli T, Brinkley BR, Bazett-Jones DP, Allis CD (1997) Mitosisspecific phosphorylation of histone H3 initiates primarily within pericentromeric heterochromatin during G2 and spreads in an ordered fashion coincident with mitotic chromosome condensation.

Chromosoma, 106:348-360.

Jackson JP, Johnson L, Jasencakova Z, Zhang X, PerezBurgos L, Singh PB, Cheng X, Schubert I, Jenuwein T, Jacobsen SE (2004) Dimethylation of histone H3 lysine 9 is a critical mark for DNA methylation and gene silencing in Arabidopsis thaliana.

Chromosoma, 112:308-315.

Obviously, the above selection is subjective and somewhat arbitrary, and I take sole responsibility for the inevitable omissions (with my sincere apologies to the authors). Importantly, though, the above papers beautifully illustrate the progress of science, beginning with an early emphasis on genetics and the cytology of giant chromosomes, followed by the implementation of groundbreaking methods for studying "normal" chromosomes, the impact of biochemistry and molecular biology, the elaboration of fundamental concepts of nuclear organization, the discovery of key nuclear proteins and nuclear bodies, all the way to the advent of the powerful technologies that dominate today's science, including advanced imaging, biophysics, proteomics, and genomics.

By definition, it takes time for any paper-no matter how brilliant - to mature into a citation classic, so the exclusion of recently published papers from the above list is deliberate. Importantly, though, excellent papers continue to be published in Chromosoma, and the examples cited below may serve to illustrate this point. I am confident that current issues of Chromosoma harbor many citation classics in the makingso please stay tuned.

Misulovin Z, Schwartz YB, Li XY, Kahn TG, Gause M, MacArthur S, Fay JC, Eisen MB, Pirrotta V, Biggin MD, Dorsett D (2008) Association of cohesin and Nipped-B with transcriptionally active regions of the Drosophila melanogaster genome.

Chromosoma, 117: 89-102.

Kubben N, Adriaens M, Meuleman W, Voncken JW, van Steensel B, Misteli T (2012) Mapping of lamin A- and progerin-interacting genome regions.

Chromosoma, 121:447-64.

Perhaps not unexpectedly, some papers never get due credit. Illustrating this final point, I thank Ingo Schubert for drawing my attention to a 1956 publication in Chromosoma: Differentielle Färbung der Somatischen Metaphase Chromosomen von Cypripedium debile; Vol. 7, 620-626. This paper is remarkable for at least two reasons. First, it was published in German, although its only author, Noriko Yamasaki, was from Japan! Second, the paper describes what may well be the first clear evidence for chromosome banding-long before $\mathrm{Q}$ banding and $\mathrm{G}$ banding became popular. To date, this paper was cited only 16 times - and citations are unlikely to pick up. Perhaps this study was simply published ahead of its time?

Let me conclude by expressing thanks and encouragements. First and foremost, I would like to thank all of youreaders, authors, referees, and associate editors-for your continuous support! Without your interest and your active contribution, Chromosoma would hardly be able to withstand the increasing pressure on scholarly "specialist journals." Please continue to provide your help and support: if you aim for publication of long-lasting truth - then Chromosoma is the place to go!

Congratulations to Chromosoma and best wishes for the next 75 years!

Erich Nigg, Chief Editor

February 2014 